\title{
DETERMINASI TINGKAT PENGUNGKAPAN BANK SYARIAH DI BEBERAPA NEGARA
}

\author{
Krisno Septyan \\ Jurusan Akuntansi, UPN Veteran Jakarta \\ Email:krisno.septyan@upnvj.ac.id; kris.tyan26@gmail.com \\ DOI: https://doi.org/10.5281/jakis.v6i2.11
}

\begin{abstract}
The purpose of this study was determine the impact of Shariah Supervisory Boards' Characteristic and Audit Firm Size against Disclosure Level. Shariah Supervisory Boards (SSB)'s Characteristic measured with Islamic Governance (IG) Score are include existent, background of education (economics and syariah), experience in economic (cross-membership and reputation in economics) and number of SSB. Audit firm size was proxied with dummy between big4 and non big4. For disclosure level measured with formulating disclosure index based on Shariah Enterprise Theory. Formulating index is compilation from few index in previously researchs. Sampel from six countries are Indonesia, Malaysia, Bahrain, Qatar, Iran and United Kingdom. Result show that all independent variables are significant to disclosure levels both with normal measure and sensitivity test.
\end{abstract}

Keywords: Audit Firm Size, Disclosure, Shariah Supervisory Board, Shariah Enterprise Theory

\section{PENDAHULUAN}

Entitas syariah sangat berkembang belakangan ini. Bukti yang memperkuat perkembangan entitas syariah adalah Pembentukan Standar Akuntansi Keuangan Syariah karena beragam transaksi syariah yang ada. Penentuan PSAK Syariah tersebut banyak berkiblat dari organisasi Islam di Timur Tengah bernama Accounting and Auditing Organization of Islamic Financial Instituion (selanjutnyadisebut AAOIFI) (Harahap, 2001).

Harahap (2002) dalam penelitiannya menemukan bahwa standar pengungkapan yang diterbitkan AAOIFI masih memiliki paham filosofi kapitalis yang kental. Sedangkan Hameed et al (2003) mencoba memformulasikan indeks pengungkapan yang lebih komprehensif namun lebih banyak pada indeks CG. Formulasi indeks pengungkapan lainnya untuk entitas syariah adalah Islamic Social Reporting (ISR) yang merupakan modifikasi beberapa peneliti terdahulu Haniffa (2002), Maali et al (2006) dan Othman et al (2009) menggambarkan corak sosial.

Keterangan di atas merupakan beberapa pengenalan indeks pengungkapan syariah dari berbagai macam sudut pandang. AAOIFI konsen pada pelaporan keuangan, ISR konsen pada pengungkapan yang bersifat sosial, dan IDI mencoba mengembangkan indeks agar lebih komprehensif, penelitian lain juga banyak yang melakukan determinan pengungkapanpengungkapan. Peneliti mencoba mengambil beberapa faktor salah satunya 
adalah Dewan Pengawas Syariah, ukuran KAP dan beberapa variabel sebagai variabel kontrol.

Prasetyoningrum (2004) bahwa terjadi penurunan kepatuhan bank syariah terhadap prinsip syariah. Berdasarkan hasil penelitian tersebut ditemukan adanya keraguan masyarakat terhadap kepatuhan syariah di bank syariah. Salah satunya dikarenakan Dewan Pengawas Syariah (DPS) belum mengawasi secara optimal.

Peneliti terdahulu meneliti bahwa DPS memberikan pengaruh yang signifikan atas kehadiran, kompetensinya terhadap pengungkapan di entitas syariah di 14 Negara dalam penelitian Farook, et al (2011). Namun DPS tidak memiliki pengaruh yang signifikan terhadap pengungkapan di beberapa Negara yang ditemukan oleh Rizkiningsih (2012).

Faktor lain yang dianggap sebagai pengaruh besarnya tingkat pengungkapan adalah kualitas audit. DeAngleo (1981) menyatakan bahwa ukuran Kantor Akuntan Publik (KAP) menentukan kualitas audit. Faktanya KAP besar memiliki hubungan dengan AAOIFI dan menerbitkan buku hasil survey perkembangan lembaga keuangan syariah dan regulasi-regulasi di Timur Tengah.

Faktor-faktor yang mempengaruhi pengungkapan di atas, memiliki regulasi berbeda di setiap negara seperti Dewan Pengawas Syariah yang menjabat di bank syariah, di Indonesia berasal dari Majelis Ulama Indonesia, di Bahrain berasal dari AAOIFI di Malaysia berasal dari bank sentral, di Inggris berasal dari Bahrain, di Iran tidak ada Dewan Pengawas Syariah. Untuk Ukuran KAP yang besar memang meiliki cabang di berbagai negara, apakah hal ini juga akan mempengaruhi pemberian servise kepada klien. Hal lain yaitu populasi muslim, apakah menjadi faktor yang mempengaruhi juga dalam memberikan informasi di laporan tahunan untuk menjaga kredibilitas bank syariah

Adapun beberapa tujuan penelitian ini adalah (1) menganalisis tingkat pengungkapan bank syariah yang diukur dengan indeks pengungkapan berdasarkan Shariah Enterprise Theory (2) untuk membuktikan secara empiris pengaruh DPS terhadap tingkat pengungkapan bank syariah dan (3) untuk membuktikan secara empiris bank syariah yang diaudit oleh KAP the big four memiliki tingkat pengungkapan lebih tinggi dibandingkan dengan bank syariah yang tidak diaudit dengan KAP non-big four

\section{TELAAH TEORITIS DAN PENGEMBANGAN HIPOTESIS}

\subsection{DEWAN PENGAWAS SYARIAH}

Berdasarkan Standar governance yang diterbitkan AAOIFI di Bahrain, pengertian DPS adalah badan independen yang dikhususkan sebagai ahli hukum dalam bidang fiqh muamalah (komersial). Namun syarat lainnya bisa juga ahli dalam bidang lembaga keuangan syariah dan memiliki pengetahuan yang cukup dalam bidang fiqh muamalah. DPS dipercaya berkewajiban langsung mereview dan mengawasi aktifitas lembaga keuangan syariah untuk 
memastikan bahwa entitas tersebut patuh pada peraturan dan prinsip Syariah Islam.

\subsection{PENGEMBANGAN INDEKS PENGUNGKAPAN DENGAN SHARIAHENTERPRISE THEORY}

Awalnya akuntansi berpedoman pada proprietary theory yaitu memiliki arti bahwa entitas bertanggung jawab atas kekayaan pemegang saham atau dengan kata lain pemegang saham merupakan pusat pertanggungjawaban (pemegang saham sebagai participant). Kemudian toeri tersebut berkembang menjadi entity theory dimana perkembangan dan keberlanjutan perusahaan menjadi hal penting dan terpisah dengan pemilik saham itu sendiri (pemegang saham menjadi outsider), maka timbul hubungan principal and agent. Triyuwono (2012) menyatakan bahwa kedua teori tersebut sangat memiliki nilai egoistic yaitu hanya mementingkan pihak manajemen dan pemilik saham dengan mengabaikan stakeholder lainnya. Padahal dalam syariah melarang kekayaan hanya beredar pada golongan tertentu. Dengan konsep khalifahtulloh fil Ardh dalam teori akuntansi syariah menerangkan bahwa manusia sebagai pemegang amanah untuk menyebarkan kesejahteraan kepada seluruh stakeholder, maka Shariah enterprise theory dianggap menjadi solusi.

Triyuwono (2012) menyatakan bahwa Shariah Enterprise Theroy merupakan dasar kegiatan bank syariah secara menyeluruh karena teori ini memperhatikan seluruh stakeholder dibanding teori-teori sebelumnya. Stakeholder yang dimaksud tidak hanya kepada pihak-pihak yang berkontribusi langsung terhadap profit, tapi juga kepada pihak yang tidak berkontribusi secara langsung dalam menghasilkan profit, termasuk mengakui keberadaan Tuhan sebagai stakeholder tertinggi.

Harahap (1997) dalam Triyuwono (2012) yang menyatakan “... Enterprise Theory menjelaskan bahwa akuntansi harus melayani bukan saja pemilik perusahaan, tetapi juga masyarakat" ditambahkan oleh Triyuwono (2012) menyatakan "akuntansi syariah tidak saja sebagai bentuk akuntabilitas manajemen terhadap pemilik perusahaan, tetapi juga sebagai akuntabilitas kepada stakeholder (termasuk alam) dan Tuhan"

Namun akuntansi masih memiliki sifat mendunia yang memahami bahwa perusahaan merupakan amanah, maka manajemen sebagai pengelola harus memberikan laporan yang dapat diukur secara manusiawi yaitu melalui pengungkapan yang memberikan informasi bahwa entitas syariah tersebut memperhatikan seluruh stakeholder. Sehingga penyajian pengungkapan tersebut memberikan informasi bahwa entitas memperhatikan hubungan dengan manusia (stockholder, investor, karyawan, nasabah dan sosial) dan hubungan entitas dengan alam. Pengungkapan kepada Tuhan tidak harus tertulis dalam laporan tahunan perusahaan karena meyakini Tuhan Maha Mengetahui (a'lim).

Dengan demikian, entitas syariah secara seimbang dapat menggambarkan nuansa akuntansi dan syariah seperti yang dinyatakan oleh Triyuwono (2006 dan 2012) memperkenalkan Epistemologi Berpasangan, 
yang terdapat dalam (QS. 36:36). Adapun isi dari QS 36:36 adalah sebagai berikut:

" Maha Suci Tuhan yang telah menciptakan pasangan-pasangan, baik dari apa yang ditumbuhkan oleh bumi dan dari diri mereka maupun dari apa yang tidak mereka ketahui."

Untuk pengukuran pengungkapan, peneliti mengkombinasi standar dari Timur Tengah dan Malaysia, adapun standar dari Timur Tengah yang diterbitkan oleh AAOIFI yaitu standar pengungkapan pelaporan keuangan, Islamic Reporting Index dan dari malaysia adalah Islamicity Disclosure Index yang mencakup Shariah Cmplinace, Governance dan Environmental/Social reporting.

Karena ada kesamaan beberapa point pada setiap indeks, peneliti menggabungkan beberapa indeks agar saling melengkapi (Septyan, 2016). Contoh: dalam IDI dan AAOIFI hanya menyarankan indeks bahwa bank syariah harus mengeluarkan laporan sumber dan penggunaan zakat, tapi ISR memberikan perincian indeks mengenai zakat lebih detail, seperti metode perhitungan zakat apa yang digunakan, mengapa ada dana zakat yang tidak disalurkan. Contoh di atas diharapkan memberikan gambaran secara detail dalam satu point seperti contoh di atas yaitu zakat. Langkah berikutnya peneliti menghilangkan indeks yang dianggap tidak dapat diterapkan secara umum dan yang tidak sesuai dengan prinsip dan hukum Islam.

Jika dilihat berdasarkan tujuan, indeks yang dikeluarkan AAOIFI memiliki tujuan pengungkapan lebih banyak kepada owner dan investor. Indeks lain adalah Islamicity disclosure indeks (IDI) merupakan suatu alternatif indeks yang dikeluarkan oleh Hameed (2003) yang mencakup berbagai aspek. Termasuk yang menggambarkan karakteristik bank syariah, terlihat dalam komponen shariah compliance. Komponen governance merupakan suatu hal penting dalam menjalankan usaha, dan komponen social/environmental menyajikan suatu pertanggungjawaban kepada pihak luar dan internal (karyawan) selama menjalankan operasional bank syariah.

Dilain hal, ISR yang merupakan ciri khas dari Corporate Social Responsibility cukup memadai untuk informasi yang disajikan kepada sosial (sesama) dan lingkungan. Secara emplisit ISR menyajikan lebih detail mengenai social dibanding pada dua disclosure lainnya. Karena ISR fokus pada dan sosial (sesama), maka aspek-aspek dalam pelaporan keuangan kurang diperhatikan.

Sedangkan standar dari AAOIFI memberikan gambaran akuntansi yang sangat kental, karena tertulis jelas pengungkapan tersebut untuk pelaporan keuangan. Padahal dalam Triyuwono (2012) menyirat makna bahwa akuntansi adalah disiplin dan praktik yang dibentuk dan membentuk lingkungannya. Dari pernyataan ini member makna bahwa akuntansi syariah dibentuk dari entitas syariah seharusnya membentuk output yang bernafaskan Islami yaitu secara seimbang tidak hanya pada pelaporan keuagnan saja tapi juga pada kepedulian sosial.

Setelah melakukan kompilasi beberapa akun. Kemudian ada beberapa point indeks akun yg dihapus dalam tiga sumber indeks (standar pelaporan 
keuangan AAOIFI, Islamicity Disclosure Index (IDI) dan Islamic Social Reporting (ISR) Index) seperti energy saving, manajemen lingkungan. Mengingat bank adalah lembaga keuangan yang menghimpun dan menyalurkan pembiayaanserta memberikan jasa perbankan lainnya bukan fokus pada lingkungan hidup dan fakta yang menunjukkan bahwa pada struktur organisasi bank syariah tidak ada manajemen yang mengatur mengenai lingkungan, maka poin tersebut tidak diperlukan sehingga keluar dari indeks.

Indeks lain yang dikeluarkan adalah governance (IDI) karena (1) berupa angka seolah memberikan kesan sebuah kewajiban, padahal tidak setiap negara memiliki peraturan dengan angka terkait tersebut (2) untuk penelitian berikutnya, jika variabel independen menggunakan CG maka tidak akan terjadi hubungan kausalitas dan (3) dalam peraturan BAPEPAM, tidak pernah termuat pengungkapan untuk governance (PBI mensyaratkan pengungkapan laporan CG, (4) beberapa bank membuat laporan CG tersendiri di luar Annual Report

Indeks lain yaitu rasio gaji antar gender pada Indeks Islamic Social Reporting dihapus, karena tidak sesuai dengan QS. An-Nahl ayat 97 yang tidak membedakan upah pekerja antar gender. Ayat tersebut memberi makna bahwa baik laki-laki maupun perempuan mendapatkan upah yang layak dan tidak membedakan gender.

Value Added Statement adalah point yang ada di indeks IDI, dan yang mengejutkannya pada penelitian Hameed et al (2013) juga tidak satu pun Bank Syariah baik Bank Bahrain maupun Bank Syariah di Malaysia mengeluarkan Value Added Statement. Dalam tataran teoritis pun, Triyuwono (2012) dan Mulawarman (2008) menyatakan Value Added Statement merupakan gagasan atas laporan keuangan syariah sebagai pengganti Laporan Laba Rugi.

\subsection{PENGEMBANGAN HIPOTESIS}

\subsubsection{Hubungan Karakteristik DPS terhadap Tingkat Pengungkapan}

Di Indonesia, DPS merupakan kepanjangan tangan DSN yang memiliki fungsi sebagai pemantau atas kinerja bank agar sesuai dengan prinsip-prinsip syariah dan memberikan inovasi produk-produk syariah. Sehingga untuk patuh terhadap syariah ditentukan juga oleh banyaknya DPS dengan beragam pandangan dan pengalaman.

Namun berdasarkan fakta yang ada menunjukan penetapan DPS hanya sebagai pelengkap perundang-undangan, hal ini menyebabkan adanya skeptisme atas kompetensi DPS.Dengan adanya sikap amanah DPS menjadi selalu memperbaharui informasi agar syariah tidak hanya sesuai syariah dalam pernyataan DPS tapi juga dapat dibuktikan melalui pengungkapanpengungkapan yang menunjukan karakteristik syariah dari standar luar negeri.

Hal yang memperkuat alasan di atas, peneliti mengambil contoh dari Indonesia adalah DPS dari DSN yang merupakan salah satu pihak yang 
merumuskan PSAK Syariah banyak berkiblat dari standar yang diterbitkan AAOIFI. Di Malaysia dan Bahrain sebagian DPS merupakan Anggota AAOIFI. Dengan demikian, seharusnya DPS dapat lebih update dan mengetahui seluk beluk segala standar AAOIFI mengenai standar pengungkapan untuk lembaga keuangan syariah. Update mengenai standar dari luar dilihat juga dari latar belakang pendidikan dalam bidang ekonomi, keuangan, perbankan dan akuntansi sehingga melihat kompetensi DPS mempengaruhi dalam dunia perbankan.

Farook et al (2011) menyatakan juga latar belakang pendidikan setiap Dewan Pengawas Syariah memiliki pengaruh penting dalam pengungkapan terhadap CSR, kerelevanan pendidikan setiap dewan pengawas syariah seharusnya dalam bidang bisnis dan syariah. AAOIFI pun merekomendasikan anggota yang menduduki jabatan Dewan Pengawas Syariah seharusnya memiliki background yang berbeda seperti ekonom, banker dan lainnya yang masih berhubungan dengan dunia perbankan. Didukung oleh AAOIFI (2003) dalam Farook et al (2011) menyatakan bahwa AAOIFI mensyaratkan baik DPS dan financial auditorsbank syariah untuk melaporkan ketaatan syariah. Dan dalam salah satu indeks IDI memuat bahwa salah satu DPS harus memiliki latar belakang pendidikan akuntansi. Sehingga, background pendidikanmerupakan bagian penting dalam penentuan DPS dalam bank syariah.

Dalam peraturan Malaysia dan Standar Governance dari AAOIFI menyebutkan bahwa selain DPS memiliki latar belakangpendidikan ekonomi, bisa juga memiliki latar belakangsyariah dan memiliki pengalaman di lembaga keuangan syariah. Farook et al (2011) menambahkan penghitungan DPS dengan IG-Score juga mengkategorikan DPS memiliki pengalaman di bidang ekonomi dan sebagainya. Maka pengalaman ekonomi patut dipertimbangkan dalam penentuan Dewan Pengawas Syariah di bank syariah.

Hal lain yang menjadi pertimbangan adalah kedudukan DPS lebih dari satu lembaga keuangan syariah sehingga memiliki pengalaman dan pengamatan berbagai kondisi lembaga keuangan syariah. Seperti Farook et al (2011) dan Rizkiningsih (2012) mengukur DPS dengan menilai dari berbagai aspek tidak hanya pada kompetensi tapi juga kedudukan DPS menempati lebih dari satu lembaga, jumlah DPS pun menjadi pertimbangan karena semakin banyak DPS akan menambah pengetahuan dari setiap rapat atau diskusi DPS tersebut.

Pernyataan tersebut sesuai dengan Dahya (1996) dalam Farook et al (2011) bahwa cross-directorship menghasilkan perbandingan pengetahuan dari entitas lainnya. Haniffa dan Coke (2002, hal.321) dalam Farook et al (2011) juga mengatakan bahwa DPS cross-membershipakan selalu berdiskui lebih banyak dengan DPS lainnya. Berdasarkan pernyataan di atas dengan didukung peneliti terdahulu dan standar yang ada, maka terbentuklah hipotesa:

\section{H1: Karakteristik DPS berpengaruh positif terhadap tingkat pengungkapan}

2.3.2 Hubungan Ukuran KAP terhadap Tingkat Pengungkapan 
Dalam Baros et al (2013) menerangkan DeAngelo (1981) menyarankan bahwa ukuran auditor sebagai proksi untuk kualitas audit dan menyediakan kualitas pelayanan yang lebih tinggi dan memilihara reputasi klien dan menghindari kehilangan customer, dengan demikian informasi yang diungkapkan lebih akurat, detail dan lebih komprehensif.

Dalam sebuah pengantar AAOIFI (2003), Farook et al (2011), Hameed et al (2003), KAP big four memiliki relasi dengan AAOIFI. Fakta lain adalah beberapa KAP besar membuat buku hasil survey di timur tengah yang didalamnya memperkenalkan AAOIFI dan beberapa standar AAOIFI. Selain itu mengingat KAP big four memiliki cabang di berbagai Negara, memungkinan untuk berbagi (sharing) peraturan Negara lain yang menunjukan KAP big four memiliki wawasan lebih luas. Sehingga KAP besar memiliki kemungkinan akan lebih patuh terhadap standar-standar yang berhubungan dengan lembaga keuangan syariah luar negeri.

Dalam Farook et al (2011) dan Hameed et al (2003) menyatakan bahwa AAOIFI mensyaratkan baik DPS dan financial auditors bank syariah untuk melaporkan ketaatan syariah. Hal ini memperkuat penyataan di atas bahwa KAP akan memberikan pelayanan lebih termasuk dalam hal pengungkapan dalam laporan tahunan. Berdasarkan pernyataan di atas didukung argumen peneliti terdahulu, maka terbentuklah hipotesa:

H2: Bank syariah yang diaudit oleh KAP big four memiliki tingkat pengungkapan lebih tinggi dibandingkan dengan bank syariah yang tidak diaudit dengan KAP non-big four

\section{METODE PENELITIAN}

\subsection{DATA DAN SAMPEL}

Sampel pada penelitian ini menggunakan metode purposive sampling, yaitu yang memiliki kriteria sampel tertentu sesuai dengan yang dikehendaki peneliti. Adapun kriteria sampel adalah sebagai berikut: (1) Diakses melalui website www.aibim.com, (2) Berbentuk Bank Umum Syariah dan memiliki website (3) Disajikan dalam Bahasa Inggris dan atau Bahasa Indonesia dan (4) Menyediakan annual report pada web bank syariah tersebut

Peneliti tidak menggunakan sampel Unit Usaha Syariah (UUS). UUS adalah bagian/divisi/unit syariah yang ada di bank konvensional. Karena Laporan tahunan masih merangkap dengan bank konvensional sehingga sulit membedakan pengungkapan mana yang menjadi pengungkapan UUS itu sendiri dengan pengungkapan induknya (bank konvensional).

Perolehan data diambil dari www.aibim.com yang memuat daftar bank syariah di beberapa negara dan memberikan akses menuju website bank syariah di setiap negara. Adapun ukuran sampel sebanyak 106 tahun perusahaan. 


\subsection{PENGUKURAN VARIABEL}

\subsubsection{Variabel Dependen}

Tingkat Pengungkapan, merupakan informasi yang tersaji mengenai bank syariah dalam laporan tahunan setiap perusahaan dengan pengembangan indeks yang telah dilakukan peneliti berdasarkan telaah literatur. Adapun garis besar tingkat pengungkapan tersebut mencakup beberapa tema yaitu informasi bagi investor, sosial dan sesama serta alam/lingkungan (Septyan, 2016).

Nilai indeks tersebut diperoleh dengan cara mendikotomi, yaitu 1 jika komponen tersebut diungkapkan dan 0 bila tidak diungkapkan berpedoman pada keyword. Kemudian dijumlahkan untuk mendapatkan score pengungkapan.

\subsubsection{Variabel Independen}

\section{a. Dewan Pengawas Syariah}

Perhitungannya diukur dengan jumlah dewan pengawas syariah, crossmembership, latar belakang pendidikan ekonomi dan atau syariah, memiliki pengalaman ekonomi dan sebagainya. Setiap komponen diberi nilai 1 bila ada dan 0 bila tidak memiliki syarat-syarat, kemudian dijumlah untuk mendapatkan IG-Score tersebut. Mengikuti perhitungan Farook (2011) dengam modifikasi seperti Rizkiningsih (2012) mengurangi beberapa perhitungan DPS. Pada Penelitian ini hanya mengganti yang memiliki pendidikan Ph.D menjadi "Backsyar" karena dalam standar governance AAOIFI menyarankan bahwa salah satu DPS harus ada yang memiliki background pendidikan syariah/hukum. Dengan demikian maka diperoleh persamaan sebagai berikut:

$$
\text { DPS }=\text { Ada }+ \text { jumDPS }+ \text { crossmem }+ \text { BackEko }+ \text { Back Syar }+ \text { PengEk }
$$

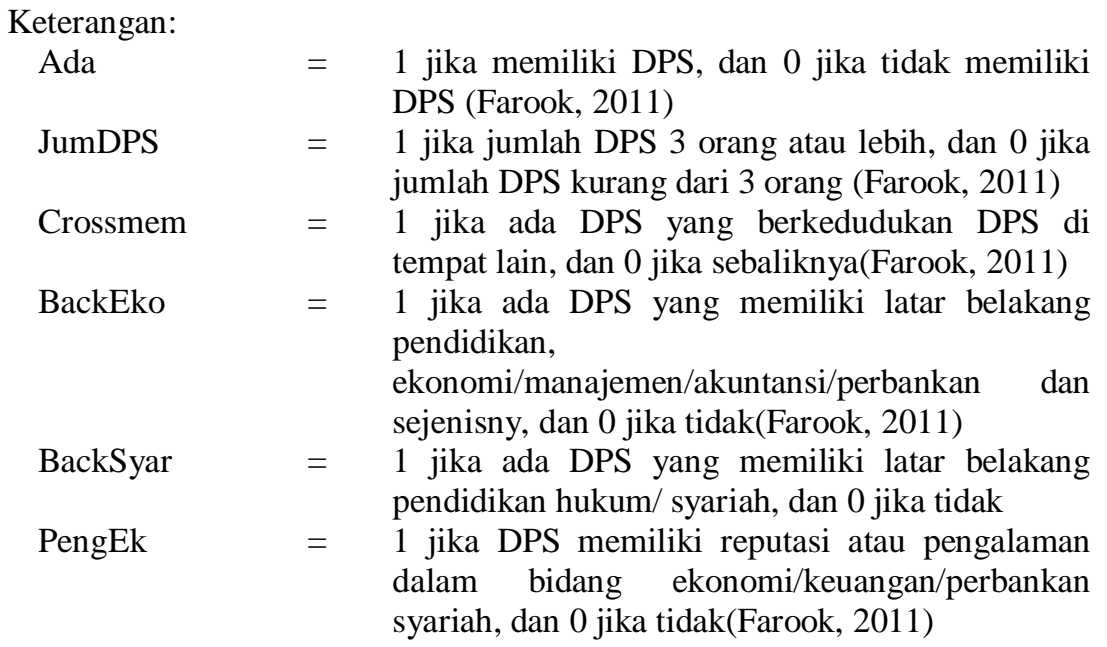


Angka-angka tersebut dijumlahkan untuk memperoleh nilai DPS. Dengan demikian, nilai DPS maksimal adalah enam.

\section{b. Ukuran KAP}

Adalah auditor independen bank syariah. Ukuran KAP diproksikan dengan model dummy seperti yang dilakukan pada penelitian Baros et al (2013), Kelton dan Yang ((2004) yaitu: 1= KAP big four (Deloitte, Ernst\&Young, KPMG dan PWC), dan 0 = selain KAP big four

\subsubsection{Variabel Kontrol}

\section{a. Ukuran Perusahaan (SIZE)}

Ukuran perusahaan diukur dengan menggunakan Total Aset setiap bank syariah, kemudian disamakan ke dalam satu jenis mata uang (US Dollar) seperti dilakukan oleh Farook et al (2011), setelah itu di-Logaritma Naturalkan untuk menghindari heteroskedastisitas. Ukuran perusahaan (SIZE) sebagai variabel control pada beberapa peneliti terdahulu diyakini sebagai pengukuran yang konsisten terhadap pengungkapan Kelton and Yang (2004), Hardiyanti (2010), Galani et al (2011) dan Baros et al (2013). Argumentasi mengenai besarnya perusahaan mempengaruhi pengungkapan terdapat pada agency dan positive accounting theory bahwa manajer menggunakan pengungkapan sebagai bagian strategi untuk mengurangi agency cost (Watts and Zimmerman, 1978).

\section{b. Profitabilitas (ROE)}

Profitabilitas merupakan kemampuan perusahaan dalam menghasilkan laba. Profitabilitas dialam penelitian ini diukur dengan Return on Equity (ROE) yaitu laba bersih dibagi ekuitas, data diperoleh dari laporan keuangan bank syariah. Peneliti lebih memilih ROE karena beberapa peneliti terdahulu menggunakannya untuk melihat pengaruh profitabilitas terhadap pengungkapan seperti Kelton dan Yang (2004), Karim dan Ahmed (2005) Rizkiningsih (2011). Alasan lain Lesakova (2005) menyatakan pemilihan rasio keuangan bagi bank seperti ROA yang menunjukan return dari aset mempertanyakan apakah seluruh akun di dalam aset seperti kas turut serta dalam menghasilkan pendapatan. Selain itu, ekuitas lebih menchapter debt karena merupakan aset dikurangi hutang. Maka peneliti mengambil ROE sebagai variabel pengendali. Kemudian peneliti melihat rata-rata dari kedua ratio tesebut dengan hasil bawhwa ROE memiliki rata-rata positif yang mendekati pada hipotesis.

\section{c. Populasi Muslim (POLIM)}

Populasi muslim dalam penelitian ini menggunakan rasio penduduk muslim. Variabel ini digunakan oleh Farook et al (2011) dan Rizkiningsih (2012). Semakin banyak penduduk muslim, maka bank syariah akan semakin 
menjaga nama baik perusahaan karena bank syariah menyadari sebagai insturmen keuangan bagi masyarakat tersebut. pengukurannya yaitu dengan membagi total penduduk msulim dengan total penduduk per Negara. Data di peroleh melalui Central Intelegency Agency (CIA) World Factbook pada website melalui internet yaitu www.cia.gov/library/publication/the-worldfactbook/

\subsection{MODEL PENELITIAN}

Model penelitian dapat dilihat pada persamaan di bawah ini:

$$
\operatorname{Discl}_{i t}=\beta_{0}+\beta_{1} K_{A P}+\beta_{2} \text { DPS }_{i t, 1,2}+\beta_{3} \operatorname{Size}_{i t}+\beta_{4} \text { ROE }_{i t}+\beta_{5} \text { Polim }_{i t}+\varepsilon
$$

Keterangan:

$$
\begin{array}{ll}
\text { Discl } & =\text { tingkat pengungkapan } \\
\mathrm{B}_{0}= & \text { konstanta } \\
\beta 1-\beta 5= & \text { koefisien regresi } \\
\text { DPS } & =\text { karakteristik Dewan Pengawas Syariah dengan dua } \\
& \text { pengukuran } \\
\text { KAP }= & 1 \text { untuk KAP big four dan } 0 \text { untuk non big four } \\
\text { Size } & =\text { Ukuran Perusahaan (Logaritma natural Total aset) } \\
\text { ROE } & =\text { Profitabilitas (Return on Equity) } \\
\text { Polim }= & \text { Populasi Muslim } \\
\varepsilon & =\text { error }
\end{array}
$$

Selain uji utama dengan model dan pengukuran seperti yang telah dijelaskan di atas, dilakukan uji sensitivitas yaitu dengan mengubah pengukuran variabel DPS dengan mengurangi komponen "keberadaan DPS" sehingga angka maksimalnya adalah 5, dan bank syariah yang tidak memiliki DPS dikeluarkan dari sampel.

\section{HASIL DAN PEMBAHASAN}

\subsection{ELIMINASI SAMPEL}

Berdasarkan informasi perolehan data, tidak semua laporan tahunan setiap bank syariah dapat diperoleh. Dengan perincian sebagai berikut:

Tabel 1. Eliminasi Sampel

\begin{tabular}{cc}
\hline Keterangan pengeliminasian sampel & Jumlah sampel \\
\hline Jumlah Negara dalam website www.aibim.com & 51 \\
\hline Bank syariah yang bisa diestimasi bisa diakses & 60 \\
\hline - Web bank syariah masih dalam perbaikan & $(10)$ \\
\hline
\end{tabular}


- Bahasa asing (arab, thailand, turkey, dan lainnya)

Total bank syariah yang bisa diakses annual report 31

Dari tabel 1. di atas menunjukan ada 31 bank syariah yang bisa diakses. Beberapa bank syariah tidak dapat di akses annual report-nya karena ada yang tidak memiliki web, peneliti terkendala dengan bahasa asing seperti Arab, Thailand, Turkey dan lainnya). Serta beberapa memiliki website yang masih dalam perbaikan.

\subsection{STATISTIK DESKRIPTIF}

Tabel 2. Statistik Deskrisptif Variabel Dependen

\begin{tabular}{lccccccc}
\hline & Indonesia & Malaysia & Bahrain & Qatar & Iran & UK & All \\
\hline Maksimal & 26 & 17 & 23 & 16 & 13 & 13 & 26 \\
\hline Minimal & 9 & 10 & 10 & 10 & 9 & 13 & 9 \\
\hline Rata-rata & 17,91 & 13,13 & 15,53 & 13,28 & 11 & 13 & 15,24 \\
\hline $\mathrm{N}$ & 34 & 24 & 32 & 7 & 8 & 1 & 106 \\
\hline
\end{tabular}

Secara keseluruhan, rata-rata pengungkapan bank syariah dari ketiga negara tersebut sebesar 15,24 point atau setengah kurang sedikit $(0,26)$ dari seluruh indeks pengungkapan. Untuk tiga negara dengan jumlah sampel yang besar, Indonesia merupakan negara yang menyandang predikat pengungkapan dengan score maksimal dan score minimal. Hal ini mengindikasikan peningkatan pengungkapan di Indonesia dari tahun ke tahun cukup signifikan dibanding negara lainnya.

Tabel 3. Statistik Variabel Independen

\begin{tabular}{crrr}
\hline Variabel & \multicolumn{2}{c}{ Mean } & \multicolumn{2}{c}{ Maks } & \multicolumn{1}{c}{ Min } \\
\hline DPS & 4,764 & 6,000 & 0,000 \\
\hline Size $($ US $\$)$ & 3.330 .306 .960 & 42.794 .730 .000 & 9.749 .814 \\
\hline ROE & 0,064 & 0,6777 & $-1,1371$ \\
\hline Polim & 0,784 & 0,980 & 0,027 \\
\hline
\end{tabular}

Berdasarkan tabel 3 menjelaskan mengenai rata-rata deskriptif variabel independen DPS, Size dan ROE. Variabel DPS memiliki nilai ratarata4.318 yang mendekati nilai maksimal yaitu 5. Ini mengindikasikan karakteristik dewan pengawas syariah sebagian besar memenuhi standar yang ada. Untuk populasi muslim, tertinggi berada di Iran dan terendah 2,7\% berada di Inggris dengan rata-rata populasi muslim adalah78,4\%

Tabel 4. Frekuensi Variabel Independen Dummy (KAP)

\begin{tabular}{lcc}
\hline & \multicolumn{2}{c}{ Ukuran KAP } \\
\hline Frekuensi & Big4 & Non-Big4 \\
\hline Persentase $(\%)$ & 79 & 27 \\
\hline
\end{tabular}


Variabel dummy yaitu Ukuran KAP pada tabel 4.5. menunjukan bahwa 79 bank syariah menggunakan KAP besar atau sebesar 74,5\% dari total sampel. Sisanya, 27 bank sebesar 25,5\%menggunakan KAP non besar.

\subsection{PENGUJIAN HIPOTESIS}

Setelah melalui uji asumsi klasik dengan kesimpulan bahwa data-data yang digunakan tidak mengalami bias, maka peneliti melanjukan meregresi dengan hasil dari Eviews 6 sebagai berikut.

Tabel 5. Hasil Uji Regresi Berganda

\begin{tabular}{|c|c|c|c|}
\hline Variabel & Ekspek sign. & Coef. & p-prob \\
\hline $\mathrm{C}$ & & -4.4130 & 0.4194 \\
\hline KAP & + & 3.8176 & $0.0045^{* * *}$ \\
\hline DPS & + & 0.5534 & $0.0589 * *$ \\
\hline Size & + & 0.4261 & $0.0569 * *$ \\
\hline ROE & + & 3.1364 & $0.0258 * *$ \\
\hline Polim & + & 6.4961 & $0.0297 * *$ \\
\hline
\end{tabular}

Ket. Variabel: KAP1 untuk big four dan 0 untuk non big four; DPS sesuai pengukuran awal; LnSize = Ukuran Bank Syariah (Logaritma natural Total aset); ROE = Return on Equity; Polim $=$ persentase Populasi muslim dari seluruh penduduk per Negara

Ukuran Kantor Akuntan Publik (KAP) terbukti berpengaruh positif bahwa Ukuran KAP memberikan kualitas audit, penyediaan jasa dan memiliki pengetahuan lebih mendalam mengenai entitas syariah karena pengalaman dan relasi dengan lembaga syariah seperti AAOIFI dibanding KAP yang tidak besar. Sehingga dapat memberikan masukan-masukan kepada klien, termasuk dalam penyajian pengungkapan. Maka KAP besar yang dipilih klien bank syariah dapat menjadi pertimbangan untuk memberikan nilai lebih bagi bank syariah.

DPS berpengaruh signifikan terhadap pengungkapan, sehingga dalam memilih DPS dengan memperhatikan background pendidikan, dan pengalaman. Harus ada yang memiliki background pendidikan ekonomi dan syariah, sedangkan pengalaman DPS bisa dari pengalaman dalam bidang keuangan/perbankan dan sejenisnya serta pengalaman sebagai DPS di lembaga keuangan syariah lain. Semua hal tersebut merupakan karakteristik DPS yang berkompeten untuk menjabat di bank syariah. Bahkan jika perlu, diadakan fit and proper test dalam memilih dan mengangkat DPS.

Untuk variabel profitabilitas. Walaupun pada hakikatnya bank syariah tidak hanya mementingkan profit, namun juga mementingkan stakeholder 
lainnya seperti sosial dan alam. Namun profitabilitas menjadi dukungan atas pemberian informasi dalam pengungkapan di laporan tahunan perusahaan.

Populasi muslim juga sangat mempengaruhi pengungkapan. Karena banyaknya muslim memberikan iklim ingin tersedianya instrumen keuangan berbasis syariah sebagai prinsip kehalalan dalam berinvestasi dan menyimpan uang mereka. Sehingga hal ini menjadi dorongan bagi lembaga keuangan syariah untuk tetap menjaga nilai-nilai kebaikan di mata masyarakat, salah satunya dengan pengungkapan.

Tabel 6. Hasil Uji Sensitivitas

\begin{tabular}{lccr}
\multicolumn{4}{c}{ Discl $_{i t}=\beta_{0}+\beta_{1} \mathrm{KAP}_{i t}+\beta_{2} \mathrm{DPS}_{i t}+\beta_{3} \mathrm{Size}_{i t}+\beta_{4} \mathrm{ROE}_{i t}+\beta_{5}$ Polim $_{i t}+\varepsilon$} \\
\hline Variabel & Ekspek sign. & Coef. & p-prob \\
\hline $\mathrm{C}$ & & -6.6948 & 0.2240 \\
\hline $\mathrm{KAP}$ & + & 2.9007 & $0.0308^{* *}$ \\
\hline $\mathrm{DPS}$ & + & 0.4205 & 0.2058 \\
\hline Size & + & 0.4930 & $0.0428^{* *}$ \\
\hline $\mathrm{ROE}$ & + & 3.6082 & $0.0136^{* * *}$ \\
\hline Polim & + & 10.7063 & $0.0007^{* * *}$ \\
\hline *,**,*** signifikan masing-masing pada level 10\%, 5\% dan 1\%. didasarkan pada two-tailed test \\
untuk prediksi yang ditandai. Fstat p-prob $0.0000 .$, Adj. $\mathrm{R}^{2}=53,44 \%$
\end{tabular}

Ket. Variabel: KAP1 untuk big four dan 0 untuk non big four; DPS dengan pengubahan pengkuruan "keberadaan DPS" dihilangkan; LnSize = Ukuran Bank Syariah (Logaritma natural Total aset); ROE = Return on Equity; Polim = persentase Populasi muslim dari seluruh penduduk per Negara

Uji sensitivitas di atas dilakukan dengan cara merubah pengukuran variabel DPS dengan melihat background ekonomi, background syariah, crossmembership, jumlah DPS dan pengalaman ekonomi. Satu pengkuruan dihilangkan yaitu "keberadaan" DPS, karena penentu atas score lainnya, di anggap satu pengukuran tersebut tidak relevan dengan lainnya. Dengan demikian, bank syariah yang tidak memiliki Dewan Pengawas Syariah di keluarkan dari sampel, sehingga total sampelnya sebanyak 96 bank syariah.

Dapat dilihat bahwa hanya DPS yang tidak berpengaruh signifikan terhadap pengungkapan yang mungkin disebabkan karen DPS belum konsen pada hal pengungkapan, namun jika memasukan bank syariah yang tidak memiliki DPS dengan pengukuran awal, maka DPS berpengaruh signifikan karena menggambarkan tingkat pengungkapan yang lebih baik bank syariah yang memiliki DPS dan yang tidak seperti pada tabel 6 di atas.

\section{SIMPULAN}

Dari seluruh pengujian empiris yang telah dilakukan, maka kesimpulannya sebagai berikut (1) Content analysis menunjukan bahwa bank-bank syariah masih lebih banyak konsen pada pengungkapan pelaporan keuangan dibandingkan dengan pengungkapan yang bersifat sosial kepada seluruh 
stakeholder. (2) Pemilihan KAP menjadi penting dalam menaikan nilai kebaikan perusahaan dalam hal pengungkapan pada laporan tahunan. (3)Karakteristik DPS berpengaruh signifikan terhadap tingkat pengungkapan, menunjukan DPS ikut memajukan nilai-nilai kebaikan bagi bank syariah. Dengan demikian pemilihan DPS dapat dilihat dari kompetensi, jika perlu adakan fit and proper test dalam pemilihan dan pengangkatan DPS. (4) Profitabilitas menjadi hal penting, Karena semakin besar profitabilitas bank maka semakin tinggi pengungkapan pada bank syariah, karena bisa mengeluarkan biaya lebih banyak dalam membuat pengungkapan. (5) Populasi Muslim sangat mempengaruhi sebagai bentuk menjaga kredibilitas bank syariah di mata masyarakat yang menginginkan instrumen keuangan syariah.

Beberapa kterbatasan pada penelitian ini adalah (1) Jumlah sampel sangat sedikit hanya pada enam Negara, serta jumlah bank umum syariah masih relatif sedikit dan tidak menggambarkan kesimpulan secara global. (2) Pengembangan indeks hanya merujuk pada tiga standar pengungkapan saja, dan tidak membedakan antara pengungkapan yang wajib dengan pengungkapan sukarela. (3) Variabel pengendali yang digunakan adalah variabel pengendali yang bisa dipakai pada peneliti terdahulu yang bukan bank syariah, sedangkan dalam struktur pelaporan keuangan cukup berbeda sehingga apakah cocok atau tidak rasio keuangan tersebut yang menggambarkan bank syariah

Terkait dengan keterbatasan penelitian yang ada, maka penulis memberikan beberapa saran untuk penelitian selanjutnya, yaitu: (1) Menambahkan jumlah Negara dan bank syariah sehingga dapat menyimpulkan hasil secara mendunia dan tambah variabel untuk menyempurnakan model penelitian. (2) Tambahkan telaah literature pada indeks pengungkapan yaitu regulasi dari Negara lain agar indeks pengungkapan bisa digunakan diseluruh dunia yang bisa membedakan pengungkapan mana yang wajib dengan sukarela. Telaah lainnya yaitu dengan pendekatan nilai-nilai agama agar lebih mantap dalam mencerminkan indeks pengungkapan baik secara umum dan secara syariah. Dan (3) Menambahkan variabel pengendali seperti rasio keuangan yang menggambarkan rasio kinerja perbankan syariah.

\section{DAFTAR PUSTAKA}

AAOIFI. (2010). Accounting, Auditing and Governance Standar o Islamic Financial Instituions. Accounting and Auditing Organization for Islamic Institution. Manama, Bahrain

Baros, C. P., Boubaker, S. \& Hamrouni, A. (2013). Corporate Governance and Voluntary Disclosure in France. Journal of Applied Business Reseach. 29(5), pp 561-577 
DeAngelo, L.E. (1981). Auditor Size and Audit Quality. Journal of Accounting and Economic, 3(3), pp $183-199$.

Farook, S., Hassan, M.K. Lanis, R.(2011). Determinants of Corporate Social Responsibility Disclosure: The Case of Islamic Banks. Journal of Islamic Accounting and Business Research. 2(2), pp 114-141

Galani, D., Gravas, E. \& Stavropoulus, A. (2011). The Relation Betewwn Firm Size and Environmental Disclosure. International Conference on Applied Economics,pp 179-186

Hameed, A. Wirman, A., Alrazi, B., Nazli, M,. (2003). Alternative Disclosure \& Performance Measures for Islamic Banks. Paper Presented in the International Conference on Information System and Islam at the IIUM. Kuala Lumpur. Hal. 1-34

Haniffa, R. (2002). Social Reporting Disclosure: An Islamic Perspective. Indonesian Management and Accounting Research. 1(2), pp. 128-146

Harahap, S.S., (2001). Kritik Terhadap Perbankan Syariah, IAI \& AAOIFI. Media Riset Akuntansi, Auditing dan Informasi, 1(3), Universitas Trisakti

Harahap, S.S., (2002). The Disclosure of Islamic Value - annual Report The Analysis of Bank Muamalat Indonesia's Annual Report. Journal of Islamic Economics.Iqtisad.

Hardiyanti, S.(2012). Analisis Hubungan Shari'a Governance Structure Terhadap TIngkatPengungkapan CSR pada Perbankan Syariah di Indonesia. Skripsi. Universitas Indonesia

Kelton, A dan Yang, A. (2004). Impact of Corporate Governance to Internet Financial Reporting. Journal of Accounting and Public Policy, 1(27), pp $68-87$

Lesakova, L. (2007). Uses and Limitation of Profitability Ratio Analysis in Managerial Practice. $5^{\text {th }}$ International Conference on Management, Enterprise and Benchmarking. Matej Bel University

Mulawarman, A.D. (2008). Laporan Keuangan Syari'ah Berbasis Tazkiyah. Disertasi. Fakultas Ekonomi Universitas Brawijaya. Malang

Rizkiningsih, P. (2012). Faktor-faktor yang Mempengaruhi Pengungkapan ISR: Studi Empiris pada Bank Syariah di Indonesi, Malaysia dan Negara-negara GCC. Skripsi. Universitas Indonesia.

Septyan, K. (2016). Reformulasi Indeks Pengungkapan Bagi Entitas Syariah dan Keunikan Kebijakan Syariah di Beberapa Negara. Jurnal Equity 19(2), Jakarta.

Triyuwono, I. (2006). Akuntansi Syariah: Menuju Puncak Kesadaran Tuhan Manunggaling Kawulo-Gusti. Pidato Pengukuhan Guru Besar Akuntansi Syariah. Universitas Brawijaya. Malang 
Triyuwono, I. (2012). Perspektif, Metodologi dan Teori Akuntansi Syariah, edisi dua. Jakarta. Rajawali Pers. 